\title{
Born Digital: Are They Really Digital Natives?
}

\author{
Su-Ting Yong and Peter Gates
}

\begin{abstract}
The aim of this study was to explore the pre-university students' experience in using digital technology and investigate if they are classified as Digital Native. Data was collected using a questionnaire and $\mathbf{1 3 5}$ pre-university students participated in this study. It was found that female students expressed more frequent use of cell phone for calling/ texting and listen to music, compared to male students. However, male students play computer games more often than female students. It was also found that students are heavy Internet users and most of them have full access to smart phone, mobile computer and broadband Internet. Generally, the pre-university students are digital natives but surprisingly, female students are characterized to be more digital natives.
\end{abstract}

Index Terms-Digital native, digital technologies, Internet, multitasking.

\section{INTRODUCTION}

Advancement in science and technology has gradually transformed our life and society. Today's students are not the same as those in the past; they were born in a digital age and technologies are an integral part of their lives. They are surrounded by digital technologies and spend a lot of their time watching television, surfing the internet, playing games, using mobile phones, etc. When today's students come into the classroom - instead of copying down notes written on the whiteboard, they are more likely now to take a snapshot using their smart phone or tablet PC; instead of having face-to-face conversation in the class, they post their updates and messages to Facebook; instead of going to the library to search for information, they use Google to search the Internet Obviously, the thinking and learning approaches of today's students have radically changed. Whilst a lot of educators are aware of this, many choose to ignore and assume that students are the same as they have always been, and that the same teaching methods will continue to work for all generation of students [1], [2]. In fact, today's students are no longer the people our educational system was designed to teach [1]. Understanding how students react to technologies enables educators to know whether students have a desire to use technology for learning in ways that characterize them as digital natives [3].

Manuscript received August 4, 2013; revised October 8, 2013.

Su-Ting Yong is with the The University of Nottingham Malaysia Campus, Jalan Broga, 43500 Semenyih, Selangor Darul Ehsan, Malaysia (e-mail: Su-Ting.Yong@nottingham.edu.my).

Peter Gates is with School of Education, The University of Nottingham, Jubilee Campus, Nottingham NG8 1BB (e-mail: Peter.Gates@nottingham.ac.uk).

\section{LITERATURE REVIEW}

\section{A. What Is Digital Native?}

The terms, "digital native" and "digital immigrant" were initiated by Prensky [1]. Digital native refers to the students nowadays who are the native speakers of the digital language of computers, video games and the Internet. Today's students have grown up and spent their entire lives surrounded by computers, video games, cell phones and all other digital technologies, which have integrated into their lives. Conversely, digital immigrant refers to those who were not born into the digital world but adopted new technologies at some later point in their lives [1].

Digital natives received digital input while growing up, thus the functioning of their brains are most likely to be different as they think differently from digital immigrants [2]. They have a "hypertext mind", "leap around", parallel cognitive structure and not sequential. Digital natives are characterized as (a) used to receiving fast information, (b) like parallel process, (c) multitasking, (d) graphic first, (e) random access, (f) function best when networked, (g) thrive on instant gratification and frequent rewards (h) prefer games to serious work and (i) twitch-speed [1], [2].

One of the biggest problems faced by today's education system is the digital immigrant teachers, who speak an outdated language (pre-digital age) and find themselves struggling to teach digital native students, who speak an entirely new language [1]. Digital Natives often have short attention spans with traditional old teaching style, but not for the thing interest them [2]. Teachers have to be aware that today's students are different from those in the past. Students nowadays think and learn differently and being an educators, teachers should understand students' interest, communicate in the language of their students and use an improved teaching approach that best fitted into students' learning needs. Teachers must know how to grasp students' attention and interest in the classroom. In fact, understanding of how students react to technology in learning, social and collaborative situations is vitally important to allow teachers to accommodate their students' learning needs by employing more effective teaching approaches [3].

\section{B. Technology Usage of Digital Natives}

Before leaving the college, today's digital native students will have spent over 10,000 hours playing videogames, over 20,000 hours watching television and over 210,000 hours communicating through emails, cell phones and instant messaging, but only spend at most 5,000 hours reading books [2]. Data obtained from the Kaiser Family Foundation showed that teenagers ( 8 to 18 years old) spent more than 7.5 hours daily watching television, listening to music, surfing the web, communicating in social network and playing computer game [4]. Furthermore, research conducted by 
Professor Steven Brint conducted in California found that university students spent 41 hours per week on social and leisure activities and only allocated 28 hours to academic study [5]. Based on this finding, the largest amount of time spent on Internet usage is on Facebook, an average of 10.5 hours per week. Other research has similar findings, whereby students spent an average of 1 hour 41 minutes per day on Facebook [6]. Facebook is the largest social network in the world [7] with more than 1.06 billion monthly active users in December 2012 [8]. USA has the largest number of Facebook users (159 million) and in Malaysia, there are about 13.4 million Facebook users, which is $47.3 \%$ of Malaysian population. Among Malaysian Facebook users, males contribute $53.5 \%$ and females only $46.5 \%$. The largest Facebook Malaysian users age 18-24 years old (34.5\%) [9].

In the past few years, many researchers have been investigating digital native students' experience of using digital technologies. One of the major studies was conducted by Kennedy et al. [10] to determine first year university students' experiences with technology in Australia. Their findings showed that those students had a high unrestricted access to many digital technologies such as mobile phone (96\%), desktop computers (90\%), digital camera (76\%), memory stick (73\%), MP3 player (69\%), laptop (63\%), broadband $(73 \%)$ and game console $(47 \%)$.

In Malaysia, a similar study was conducted among pre-university and first year students in 2009 and found that all students own mobile phones [11]. Besides a mobile phone, students own a desktop computer (46.3\%), laptop computer (25.2\%), iPod audio player (44.4\%) and PDA (4.8\%). In the study, students were reported to spend most of their time using digital devices for communication or entertainment and less for academic or collaboration. The researchers claimed that Malaysian digital natives have similar habits as U.S. and Australian digital natives. Besides these two studies, other similar studies were conducted in United Kingdom [12], Hong Kong [13] and South Africa [14].

\section{METHOD}

\section{A. Aim of the Study}

The purpose of this study is to explore students' use of digital technologies and to determine the level of students characterized as digital natives. A practical contribution to this study is to understand pre-university students' need to use of technologies for learning in ways that characterize digital natives. The objectives of the study were:

1) To explore students' accessibility to digital technologies.

2) To explore students' technology usage.

3) To investigate level in which students characterized as digital native.

\section{B. Sample}

The participants were pre-university students from a private university in Malaysia. All the students' were aged between 16 to 18 years old and they have just finished their high school education.

\section{Instrument}

In this study, questions on technology accessibility were adapted from Kennedy, et al. [10] and the Digital Natives Assessment Scale (DNAS) developed by Teo [3] was used to measure attributes of digital natives. Although, the DNAS was newly developed, it is statistically valid and reliable, with easy and simple to used instructions. Furthermore, all the factors measured in DNAS strongly relate to characteristics of the digital native defined by Prensky [1], [2]. DNAS is a self-reported instrument designed to measure students' perceptions of the degree to which they are digital natives. DNAS consists of 21 items with four subscales: grow up with technology [TEC], comfortable with multitasking [MUL], reliant on graphics for communication [GRA] and thrive on instant gratifications and rewards [INS]. A Likert scale is used to indicate the extent of students' agreement with each statement. A seven-point scale from strongly disagree to strongly agree (scored from 1 to 7 ) is used for all the subscales. The scores from these items can be summed (ranging from 21 to 147) and a higher score indicating a level closer to be a digital native. DNAS is cost effective and it is available to be used by educators to enable them to understand how their students react to technology in learning, social and collaborative situations [3].

\section{Data Collection}

Data was collected from all pre-university students during their first week of study in July 2013. A soft copy of the questionnaire was posted in Moodle. Students responded to the questionnaire and submitted their responses by uploading the completed questionnaire back into Moodle. The survey is entirely voluntary.

\section{DATA ANALYSIS AND Discussion}

Data was obtained from 135 pre-university students with a response rate of $88 \%$. There are 38 males and 97 females with 123 local and 12 international students.

\section{A. Students' Access to Technology}

Students were asked about their access to a range of technology (desktop computers, smart phones, tablet PC, portable computer, etc.) and their access to the Internet. The results are shown in Table I.

TABLE I: TECHNOLOGIES ACCESSIBILITY IN PERCENTAGE

\begin{tabular}{lcccc}
\hline \hline Technologies & $\begin{array}{c}\text { Unrestricted } \\
\text { Access }\end{array}$ & $\begin{array}{c}\text { Limited } \\
\text { Access }\end{array}$ & $\begin{array}{c}\text { No } \\
\text { Access }\end{array}$ & $\begin{array}{c}\text { Not sure/ } \\
\text { missing }\end{array}$ \\
\hline Desktop Computer & $\mathbf{5 0 \%}$ & $35 \%$ & $10 \%$ & $4 \%$ \\
Video game console & $13 \%$ & $30 \%$ & $\mathbf{5 0 \%}$ & $7 \%$ \\
Mobile computer & $\mathbf{8 8 \%}$ & $10 \%$ & $2 \%$ & $0 \%$ \\
Tablet PC & $\mathbf{3 9 \%}$ & $22 \%$ & $38 \%$ & $2 \%$ \\
MP3 Player & $\mathbf{4 1 \%}$ & $24 \%$ & $33 \%$ & $2 \%$ \\
Portable DVD player & $22 \%$ & $27 \%$ & $\mathbf{4 7 \%}$ & $5 \%$ \\
Digital/video camera & $\mathbf{3 9 \%}$ & $34 \%$ & $24 \%$ & $3 \%$ \\
Cell phone & $36 \%$ & $19 \%$ & $\mathbf{3 9 \%}$ & $6 \%$ \\
Smartphone & $\mathbf{8 7 \%}$ & $5 \%$ & $8 \%$ & $0 \%$ \\
Home Broadband & $\mathbf{6 7 \%}$ & $22 \%$ & $10 \%$ & $1 \%$ \\
Mobile Broadband & $\mathbf{6 2 \%}$ & $23 \%$ & $15 \%$ & $1 \%$ \\
\hline \hline
\end{tabular}

Table I shows that majority of students have unrestricted access to different types of computers whether they are 
desktop (50\%), mobile (88\%) or tablet $(39 \%)$ personal computer. As expected, a very high proportion of students have unrestricted access to mobile computers $(88 \%)$ such as laptop, notebook, etc. as compared to desktop computers $(50 \%)$, while none only $2 \%$ of students have no access to mobile computers. The result contradicts finding by Kennedy et al. [10], whereby more students were reported to have a desktop computer (90\%) as compared to mobile computer (63\%). This is an indication that mobile computing has gained in popularity due to its affordable price to be owned by many students nowadays. Possibly, a majority of the students have no access to a dedicated DVD player (47\%) and video game console (50\%) because they own a desktop or mobile computer that can play DVDs and allow game playing. Additional analyses showed that only about $40 \%$ of students have unrestricted access to MP3 player and dedicated digital/video camera. This result is so much lower compared to what was reported by Kennedy et al. [10], whereby MP3 player (69\%) and digital camera (76\%). A decline in electronic gadget accessibility (i.e. MP3 player, digital camera) is not surprising with the recent mobile market penetration by smartphones. Today, smartphones have quickly embedded themselves into the lives of many people [15] and they come with many new special functions and improved features that imitate many electronic gadgets. As projected, $87 \%$ of students have unrestricted access to smartphone (only $8 \%$ no access) and in US, almost $47 \%$ of the US teens age 12 to 17 own smartphones [16]. Since the accessibility to smartphones is high, only $36 \%$ of students have unrestricted access to a regular cell phone and many students (39\%) have no access to it. A smartphone is considerably much more popular among the students. Being technologically savvy is reflected by digital native students. With respect to internet access, $67 \%$ and $62 \%$ of students reported having unrestricted access to home and mobile broadband respectively. Access to mobile broadband is comparable to home broadband, as the smartphones and mobile computers enable Internet access at anywhere and anytime. Heavy internet usage among students is reflected in Table II.

\section{B. Students' Technology Usage}

Students were asked about their daily technology usage (surfing Internet, making phone call/ messaging, accessing Facebook, etc.) and academic activities. The results are shown in Table II.

Among all the activities shown in Table II, surfing the internet (non-academic purpose) is the most popular activity among the students, followed by talking on the phone or sending messages and thirdly, listening to music. On average, students spent 3.77 hours per day surfing the internet. Female and local students are reported to spend more time on the Internet. However, the differences are not significant between male and female, and also local and international students. Besides surfing the Internet, students spent about 3.44 hours per day on phone call/messaging and about 3 hours listening to music. Female students spend more time in both activities (3.88 hours per day on phone call/messaging, 3.25 hours listen to music), compared to male students (3.23 hours per day on phone call/messaging, 2.37 hours listen to music), and these differences are significant $(p<0.05)$.
Looking at the nationality, local students are reported to spend more time on cell phone and listen to music. However, the differences are not significant. Additional analyses showed that male students spend about 2.75 hours per day playing digital game, whereas female students only spend 1.68 hours and the difference is significant at $p=0.05$ level. With regard to television, students spend an average of 2.72 hours per day watching television. Local students ( 2.85 hours) watch television more often than international students $(1.42$ hours) and the difference is significant at $p=0.01$ level. In this case, male students watch television more than female student, but the difference is not significant. While social networking has recently grabbed headlines in the media [7]-[9], students spend 2.58 hours daily on Facebook and the number of hours spend is higher than the previous findings found, 1.5 hours [5] and 1.68 hours [6].

TABLE II: Average OF Hours SPENT PER DAY

\begin{tabular}{lccccc}
\hline \hline & Male & Female & Local & Int'l & Total \\
\hline \hline Entertainment & & & & & \\
Internet & 3.61 & 3.84 & 3.88 & 2.62 & 3.77 \\
Phone call/message & $\mathbf{2 . 3 2} * *$ & $\mathbf{3 . 8 8}^{* *}$ & 3.49 & 2.96 & 3.44 \\
Facebook & 2.49 & 2.62 & 2.65 & 1.92 & 2.58 \\
Digital game & $\mathbf{2 . 7 5 *}$ & $\mathbf{1 . 6 8 *}$ & 1.99 & 1.92 & 1.98 \\
Watch TV & 2.76 & 2.71 & $\mathbf{2 . 8 5 * *}$ & $\mathbf{1 . 4 2} * *$ & 2.72 \\
Listen to Music & $\mathbf{2 . 3 7 *}$ & $\mathbf{3 . 2 5 *}$ & 3.01 & 2.92 & 3.00 \\
\hline \hline Academic & & & & & \\
Homework & $\mathbf{1 . 7 8 * *}$ & $\mathbf{3 . 1 4} * *$ & 2.79 & 2.46 & 2.76 \\
Revision & $\mathbf{1 . 7 0 * *}$ & $\mathbf{2 . 8 0} * *$ & 2.47 & 2.75 & 2.49 \\
\hline \hline
\end{tabular}

*sig. $p<0.05, * *$ sig. $p<0.01$

On average, students spend almost 2 to 3 hours per day doing homework and revision. It is very obvious that female students spend more time doing their homework (3.14 hours) and revision (2.8 hours), compared to male students (homework 1.78 hours; revision 1.7 hours). The time differences between male and female students in doing homework and revision are significant $(p<0.01)$.

In general, students tend to spend more time on entertainment rather than for academic purpose. This result supports the findings in [4], [5] and [11]. However, it has to be recapped that students nowadays are multitasking (e.g. they can surf internet, chat on the phone and listen to music at the same time). For example, research done by Lorch cited in [2] shows that children do not watch television continuously but in fact they can distribute their attention between other activities and viewing what was informative for them in the television program. Multitasking is one of the characteristics of digital native shown in Table III.

\section{Digital Natives Assessment}

TABLE III: DigitAL NATIVES AsSESSMENT SCALE

\begin{tabular}{|c|c|c|c|c|c|}
\hline & Male & Female & Local & Int'l & Total \\
\hline$\overline{T \text { TEC }}$ & "5.85 & 6.13 & "6.05 & 6.08 & 6.05 \\
\hline MUL & 5.57 & 5.95 & 5.85 & 5.71 & 5.84 \\
\hline GRA & $4.17 * *$ & $5.06 * *$ & 4.84 & 4.53 & 4.81 \\
\hline INS & 5.51 & 5.84 & 5.79 & 5.27 & 5.74 \\
\hline $\begin{array}{l}\text { DIGITAL } \\
\text { NATIVE: }\end{array}$ & $111.1^{* *}$ & $120.8^{* * *}$ & 118.5 & 113.7 & 118.0 \\
\hline
\end{tabular}

Students were asked about their individual perceptions of the four factors used to measure students' perception of the degree to which they are digital natives: TEC - grow up with 
technology, MUL - comfortable with multitasking, GRA reliant on graphics for communication, INS- thrive on instant gratifications and rewards). The results are shown in Table III.

Cronbach's alpha of 0.93 shows that the instrument used has high internal consistency reliability. Based on data shown in Table III, surprisingly, female students are characterized to be more digitally native compared to male students (the difference is significant at $p=0.01$ ), as they scored higher in all the four factors measured: TEC, MUL, GRA, INS. One of the reasons to explain this phenomenon could be because male students prefer more outdoor activities such as sports, travelling, etc. Among all the factors measured, there is only one factor: GRA shows the significant difference $(p<0.01)$ between male and female. It shows that female students most likely to use graphics in communication (e.g. using emoticons, smiley faces in messages). Comparison between local and international students does not show any significant difference. Generally, local students are characterized to be more digitally native and they have higher scores in three factors: MUL, GRA, INS, but the differences are not significant. In general, students have highest agreement that they are grown up with technology [TEC], followed by comfortable with multitasking [MUL], thrive for instant gratifications and rewards [INS], and lastly reliant on graphics for communication [GRA]. Overall, students obtained a mean score of 118 in this instrument (ranging from 21 to 147$)$, whereby they generally agree that they are digital natives at moderate level.

\section{CONCLUSION}

In this study, it was found that among all the digital technologies, students have the highest accessibility to smartphone and mobile computers such laptops, notebooks, etc. Students show preferences towards mobile, light and portable electronic devices that enable them to communicate and access to computer and Internet at anytime, anywhere. Despite having other electronic gadgets such as digital cameras, DVD players, MP3 players, etc., most of the students are having all these features in one electronic device such as laptop and smartphone. Students spend most of their time using digital technologies to surf Internet and thus, they have high accessibility to either home or mobile broadband. This study also found that female students are spending more time making phone call, sending messages, listen to music, doing homework and revision, compared to male students. Conversely, male students are spending more time playing digital games. Local students also reported spending more time watching television. Generally, students are heavy users of digital technologies despite spending more time on entertainment than academic pursuits. Further investigation using DNAS confirmed that the result substantial, the students are digital native. These indication from our students is an important factor to inform us on how we should use technological tools to design rich and engaging learning experiences for all students and as educators, we should adapt to the ever changing characteristics of our students [10]. Future research can be improved by increase of sample size to include more diverse group of students as technologies evolve over time.

\section{REFERENCES}

[1] M. Prensky, "Digital natives, digital immigrants part 1," On the horizon, vol. 9, no. 5, pp. 1-6, 2001.

[2] M. Prensky, "Do they really think differently," On the horizon, vol. 9, no. 6 , pp.1-9, 2001.

[3] T. Teo, "An initial development and validation of a Digital Natives Assessment Scale (DNAS)," Computers \& Education, vol. 67, pp. $51-57,2013$.

[4] M. Ahuja. (2013). Teens are spending more time consuming media on mobile devices. The Washington Post. [Online]. Available: http://articles.washingtonpost.com/2013-03-13/news/37675597_1_tee ns-cellphones-video-games

[5] R. Shragge. (2010). Students spend more time in leisure activities than studying. The California Aggie. [Online]. Available: http://www.theaggie.org/2010/02/18/students-spend-more-time-in-leis ure-activities-than-studying/

[6] R. Junco and S. R. Cotton, "No A 4 U: The relationship between multitasking and academic performance," Computer \& Education, vol. 59, pp. 505-514, 2012.

[7] Begin Group. (2013). In 2013 Facebook will have 1 billion users. [Online]. Available: http://begingroup.com/en/top/news/market_news/1353

[8] R. Protalinski. (2013). Facebook passes 1.06 billion monthly active users, 680 million mobile users and 618 million daily users. TNW Europe Conference. [Online]. Available: http://thenextweb.com/facebook/2013/01/30/facebook-passes-1-06-bil lion-monthly-active-users-680-million-mobile-users-and-618-milliondaily-users/

[9] CheckFacebook. (2013). Facebook. [Online] Available: http://www.checkfacebook.com/

[10] G. E. Kennedy, T. S. Judd, A. Churchward, K. Gray, and K. Krause, "First year students' experiences with technology: Are they really digital natives," Australasian Journal of Educational Technology, vol. 24, no. 1, pp. 108-122, 2008

[11] M. C. Yuen and S. Y. Song, "Classroom conduct for digital natives learning in higher education settings," in Proc. the $2^{\text {nd }}$ International Conference of Teaching and Learning (ICTL 2009), Malaysia.

[12] A. Margaryan, A. Littlejohn, and G. Vojt, "Are digital natives a myth or reality? University students' use of digital technologies," Computers \& Education, vol. 56, no. 2, pp. 429-440, 2011.

[13] C. McNaught, P. Lam, and A. Ho, "The digital divide between university students and teachers in Hong Kong", Same places, different spaces. Proceedings ascilite Auckland, 2009.

[14] H. Thinyane, "Are digital natives a world-wide phenomenon? An investigation into South African first year students' use and experience with technology," Computers \& Education, vol. 55, no. 1, pp. 406-414, 2010.

[15] eMarketer. (2013). Smartphones Help Drive Users to Facebook. [Online]. Available: http://www.emarketer.com/Article/Smartphones-Help-Drive-Users-Fa cebook/1009816

[16] M. Madden, A. Lenhart, M. Duggan, S. Cortesi, and U. Gasser. (2013). Teens and Technology 2013. Pew Internet. [Online]. Available: http://www.pewinternet.org/Reports/2013/Teens-and-Tech.aspx

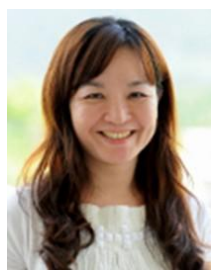

Su-Ting, Yong is an assistant professor in the department of Science Foundation at University of Nottingham Malaysia Campus. She obtained both her Bachelor and Master of Science in IT and Education from University of Technology, Malaysia. Currently, she is pursuing her $\mathrm{PhD}$ at University of Nottingham.

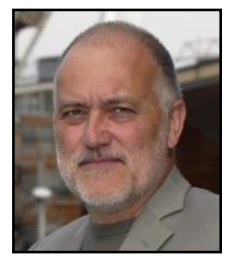

Peter Gates is an associate professor in the School of Education, University of Nottingham, where he researches in mathematics education and in areas of social justice and education. He teaches on research methods and practitioner inquiry courses. He has undertaken numerous studies on widening participation, teenage pregnancy, post-16 education and further education which have contributed to local social policy. 